\title{
CARACTERIZAÇÃO SENSORIAL, FíSICO-QUÍMICA E ACEITAÇÃO DE BEBIDAS DE CAFÉS EXÓTICOS E DE DIFERENTES CATEGORIAS BRASILEIRAS COMERCIAIS
}

\author{
MARY CARMEN MATÉ DUREK DE CONTI* \\ SANDRA HELENA PRUDENCIO**
}

\begin{abstract}
Considerando a introdução de cafés denominados exóticos no mercado nacional, e sua potencialidade de crescimento do consumo, o objetivo deste trabalho foi determinar o perfil sensorial, físico-químico e aceitação de bebidas de cafés exóticos, Jacu e Civeta, e das categorias brasileiras Tradicional, Premium e Gourmet. Foram determinados o pH, acidez titulável, sólidos solúveis, perfil sensorial e aceitação. Os dados foram tratados por Análise de variância (ANOVA), teste de Tukey e análise de componentes principais (ACP). O pH variou de 4,86 (Gourmet) a 5,34 (Tradicional), acidez titulável de $116,28 \mathrm{~mL}$ (Civeta) a 175,22 de $\mathrm{NaOH} 0,1 \mathrm{~N} / 100 \mathrm{~g}$ amostra (Gourmet) e sólidos solúveis de 1,62 (Jacu) a $2,23^{\circ}$ Brix (Tradicional). O perfil sensorial foi determinado pela análise descritiva quantitativa por 13 julgadores selecionados e treinados. Nove atributos foram avaliados; cor marrom, aparência oleosa, translúcida, aroma de queimado, sabor de queimado, gosto doce, ácido e amargo e sensação adstringente. Destes, o gosto ácido não foi importante para discriminação dos cafés. A bebida de café Jacu se distinguiu das demais por apresentar características sensoriais menos intensas, exceto para doçura. O café Civeta apresentou intensidades intermediárias nos atributos sensoriais e maior aceitação $(6,5)$ que o café Gourmet $(6,0)$ quando avaliado por 75 consumidores e escala hedônica de nove pontos.
\end{abstract}

PALAVRAS-CHAVE: CIVETA; JACU; CAFÉS EXÓTICOS; SENSORIAL.

\footnotetext{
* Mestranda em Ciências de Alimentos, Universidade Estadual de Londrina (UEL), Londrina, PR. Técnica de Laboratório, Universidade Tecnológica Federal do Paraná (UTFPR), Cornélio Procópio, PR (e-mail:mary@ utfpr.edu.br)

** Docente, Departamento de Ciência e Tecnologia de Alimentos, Universidade Estadual de Londrina, Londrina, PR (e-mail: sandrah@uel.br)
} 


\section{INTRODUÇÃO}

O café é uma bebida consumida mundialmente e de diversas formas. Alguns países têm o costume de consumi-lo com outros ingredientes, tais como, chicória, especiarias, chocolate, leite, e até com bebidas alcoólicas, como o licor (TRUGO, 2003). A prática da infusão dos grãos torrados e moídos para a obtenção da bebida de café teve início no século XVI, no Yêmen, sendo difundida para muitas partes do mundo islâmico e introduzida na Europa pelos turcos por volta do século XVII tornando-se popular em muitos países (CLARKE; MACRAE, 1985). O café chegou ao Brasil em 1727, no estado do Pará, trazido da Guiana Francesa e apenas em 1770 chegou ao Rio de Janeiro difundindo-se para os estados de São Paulo, Minas Gerais, Espírito Santo e Paraná (MORELI, 2009).

Essa bebida pertence à família botânica Rubiaceae, que tem cerca de 500 gêneros e mais de 6.000 espécies (ICO, 2009). As duas espécies de café comercializadas mundialmente são a Coffea arábica (café arábica) considerado café de alta qualidade, fino e requintado, possuindo aroma intenso e variações de sabor, corpo e acidez; e a Coffea canephora, conhecida internacionalmente como café robusta independente da variedade $(\mathrm{RONCHI}, 2011)$. No Brasil quase todo o café robusta cultivado é da variedade conilon, assim quando se refere à espécie robusta, no País, os termos "robusta" e "conilon" são utilizados como sinônimos (BRASIL, 2013). A variedade conilon não possui sabores variados e refinados como o café arábica, entretanto possui um sabor único com acidez inferior (SEAGRI, 2009).

A partir de 1989, a Associação Brasileira da Indústria de Café (ABIC) lançou o Programa do Selo de Pureza, e que ainda permanece ativo, com o intuito de alavancar o consumo da bebida de café oferecendo aos consumidores informações sobre a qualidade da bebida. Em 2004, a ABIC criou o Programa de Qualidade do Café (PQC), com a finalidade de informar a classificação do café conforme o percentual da quantidade de defeitos e suas características sensoriais, físicas, químicas e microscopias, além da identificação da espécie e variedade do grão. Em 2006, o PQC acrescentou o item categorias, classificando os cafés torrados e moídos em Tradicional (arábica blendado com conilon, sem restrição de quantidade), Premium, também conhecido como Superior (blend com até $15 \%$ de conilon) e Gourmet (somente arábica), conforme características dos produtos identificadas através da espécie do grão de café, torração, moagem, avaliação da bebida, aroma e sabor (ABIC, 2010).

O café mais caro do mundo é originário da Indonésia e denomina-se "Kopi Luwak" ou café

Civeta. Diferentemente dos cafés convencionais, os frutos maduros (cereja) do café, da espécie arábica ou robusta, são consumidos pelo civeta (Paradoxurus hermaphroditus), uma espécie de gambá, diretamente do cafeeiro. Esses frutos são despolpados durante o processo digestivo e quando defecados, os grãos são recolhidos das fezes e beneficiados. Durante a digestão, os frutos sofrem fermentação por ação de diferentes enzimas digestivas proporcionando ao café um aroma e sabor únicos, sendo descrito como terroso, azedo, licoroso, suave e rico em tons de chocolate e floresta (MARCONE, 2004). Acredita-se que o início da comercialização desse café foi em 1945, período em que a Indonésia ainda era colônia holandesa. Os grãos de cafés crus defecados pelos animais eram recolhidos pelos habitantes e entregues aos gestores da colônia em troca de dinheiro (SCHOENHOLF, 1999). No oeste da ilha a existência desse tipo de café era desconhecida até março de 1981, quando foi divulgado pela National Geographic e o artigo foi publicado como "The Bonzana Bean - Coffee" (STARBIRD, 1981). No Brasil, o café Civeta é comercializado no estado do Paraná, com preço aproximado de $\mathrm{R} \$ 1.400,00 / \mathrm{kg}$ de grão torrado (CAFEMERCADO, 2010).

O Brasil também possui um café exótico, chamado de "Jacu Bird Coffee" ou café Jacu. Diferentemente do café Civeta, os frutos são consumidos pela ave jacu (Penelope superciliaris). A descoberta desse tipo de café foi em 2006 quando parte da plantação de café orgânico, espécie arábica, da fazenda Camocim no Espírito Santo foi invadida por jacus que se alimentaram com o café ocasionando perda na produtividade. Com isso, os fazendeiros pediram autorização ao Instituto Brasileiro do Meio Ambiente e dos Recursos Naturais Renováveis (IBAMA) para eliminar as aves, enquanto aguardavam a autorização, obtiveram informações sobre o café Civeta e após testes com o café "processado" no aparelho digestivo e defecado pelas aves, decidiram comercializar o "café de 
jacu" (SANTOS, 2011). Conforme informações no site da fazenda Camocim (2009), o café Jacu possui um sabor diferenciado sendo descrito como doce, encorpado e ligeiramente mais ácido. O café torrado (torra clara) é comercializado pelo preço aproximado de R \$320,0/ kg (CAFEMERCADO, 2010).

Tendo em vista o alto custo dos cafés Civeta e Jacu e possíveis características sensoriais superiores aos cafés atualmente comercializados no Brasil, o objetivo deste estudo foi comparar as características químicas (acidez, pH e sólidos solúveis), os perfis sensoriais obtidos por meio da análise descritiva quantitativa e a aceitação de bebidas de café das classes Tradicional, Premium, Gourmet e os cafés Jacu e Civeta.

\section{MATERIAL E MÉTODOS}

\subsection{AMOSTRAS}

Foram utilizados cinco tipos de café comerciais: cafés Gourmet, Premium e Tradicional brasileiros de mesma marca; café Civeta (espécie arábica) originário da Indonésia; café Jacu (espécie arábica) originário do estado do Espírito Santo, Brasil.

As amostras foram obtidas no comércio do estado do Paraná, e os tipos Gourmet, Premium e Tradicional apresentavam-se na forma torrada (Tabela 1) e moída. Os grãos de café Jacu e café Civeta, que são comercializados como grãos torrados (Tabela 1), foram moídos na especificação de moagem média para fina ( $\mathrm{ABIC}, 2010)$. As amostras foram armazenadas em câmara fria a $5^{\circ} \mathrm{C}$ até análise.

\section{TABELA 1 - GRAU DE TORRA DAS AMOSTRAS}

\begin{tabular}{cc}
\hline Classificação & Grau de torra \\
\hline Café Tradicional & Média \\
\hline Café Premium & Média \\
\hline Café Gourmet & Média \\
\hline Café Jacu & Clara \\
\hline Café Civeta & Escura \\
\hline
\end{tabular}

Fonte: (CUNHA 2011)

\subsection{PREPARO DAS BEBIDAS}

Para as análises físico-químicas e sensoriais, as bebidas foram preparadas a partir da percolação do café torrado e moído com água purificada em Purificador Europa fervente utilizando filtro de papel próprio para café. Foram utilizados $7 \mathrm{~g}$ de café para $100 \mathrm{~mL}$ de água ( $A B I C, 2009)$.

Para a avaliação sensorial, a filtração foi realizada diretamente em garrafa térmica previamente lavada com água fervente. Para o teste de aceitação, as bebidas foram adoçadas com sacarose na proporção de 10\% (MORAES, 2009), e para análise descritiva, as bebidas não foram adoçadas.

\subsection{ANÁLISES FÍSICO-QUÍMICAS DAS BEBIDAS}

As medidas físico-químicas foram realizadas nas bebidas à temperatura ambiente.

A acidez titulável foi determinada diluindo-se uma alíquota de $5 \mathrm{~mL}$ da bebida com $50 \mathrm{~mL}$ de água destilada, em seguida a amostra foi titulada com solução de $\mathrm{NaOH}$. O resultado foi expresso

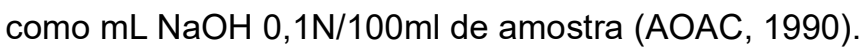

$\mathrm{O} \mathrm{pH}$ foi determinado por meio de um pHmetro de bancada da marca HANNA calibrado com soluções tampão comerciais (pH 4,00 e 7,00) (KOBAYASHI; BENASSI, 2012).

A concentração de sólidos totais foi determinada por meio de refratômetro digital de bolso da marca Atago, modelo PAL-1, previamente ajustado com água destilada (BUENAVENTURASERRANO; CASTAÑO-CASTRILLÓN, 2002). O resultado foi expresso em ${ }^{\circ}$ Brix. 


\subsection{ANÁLISE SENSORIAL DAS BEBIDAS}

As bebidas dos cafés comerciais foram submetidas à análise descritiva quantitativa e avaliadas quanto à aceitação após aprovação do projeto pelo Comitê de Ética em Pesquisa Envolvendo Seres Humanos da Universidade Estadual de Londrina - UEL (Parecer: 224/09, CAAE: 0173.0.268.000-09).

Os testes sensoriais foram realizados no Laboratório de Análise Sensorial do Departamento de Ciência e Tecnologia de Alimentos do Centro de Ciências Agrárias (CCA) da UEL, em cabines individuais, sob iluminação "luz natural do dia" e temperatura ambiente. As bebidas foram servidas a $\pm 70^{\circ} \mathrm{C}$ em copinhos de isopor descartáveis, codificados com números de três dígitos. Para as análises, os julgadores foram instruídos para preencher toda boca com as amostras das bebidas para permitir o contato com toda região e lavar a boca antes do teste e entre uma amostra e outra com água purificada em purificador Europa a temperatura ambiente.

Tanto para o teste descritivo como para o de aceitação foram recrutados julgadores que eram consumidores habituais de café, dentre alunos, docentes e funcionários do Departamento de Ciência e Tecnologia de Alimentos de CCA da universidade e que desejavam participar da equipe sensorial.

\subsection{ANÁLISE DESCRITIVA QUANTITATIVA}

\subsubsection{Seleção de julgadores}

Para avaliação da acuidade sensorial, os 25 candidatos foram submetidos aos testes de reconhecimento de gostos e odores básicos, sendo utilizada a metodologia da norma ISO 3972 (1991). Foram preparadas soluções para a detecção dos gostos doce, salgado, ácido e amargo e sensação adstringente, conforme as concentrações das substâncias apresentadas no Tabela 2. 0 critério de aprovação no teste foi de $100 \%$ de acerto.

\section{TABELA 2. SOLUÇÕES PARA TESTE DE IDENTIFICAÇÃO DE GOSTOS}

\begin{tabular}{llll}
\hline Gosto & \multicolumn{2}{c}{ Concentração } & Solução \\
\hline Doce & $0,4 \%$ & $0,8 \%$ & Sacarose \\
\hline Salgado & $0,08 \%$ & $0,15 \%$ & Cloreto de sódio \\
\hline Ácido & $0,02 \%$ & $0,04 \%$ & Ácido cítrico \\
\hline Amargo & $0,02 \%$ & $0,03 \%$ & Cafeína \\
\hline Adstringente & $0,05 \%$ & $0,1 \%$ & Ácido tânico \\
\hline Fonte: Adaptado da & &
\end{tabular}

Fonte: Adaptado da ISO 3972 (1991)

Para o teste de reconhecimento de odores, foi solicitado a cada voluntário para descrever a qualidade do odor de uma série de 15 substâncias aromáticas diferentes encontradas no cotidiano, tais como, chocolate, pó de café, caramelo, ácido acético, vinagre, erva-doce, cravo-da-índia, canela, catchup, mel, álcool etílico, iogurte natural, limão, maçã, pimenta-do-reino. O critério de aprovação foi de $60 \%$ no mínimo de acerto (WATTS et al., 1992).

Com base nos resultados dos testes de reconhecimento de gostos e odores básicos foram aprovados 16 dos 25 candidatos.

\subsubsection{Desenvolvimento de terminologia descritiva das bebidas e treinamento dos julgadores}

Os atributos sensoriais ou descritores foram levantados utilizando-se o método de Rede Kelly (Kelly's Repertory Grid Method) (MOSKOWITZ, 1995) pelos julgadores pré-selecionados. As amostras utilizadas foram cafés Tradicional, Premium e Civeta. Por meio de consenso entre os julgadores foram levantados nove descritores (atributos), elaborados o glossário com definições 
de cada termo descritivo (Tabela 3 ) e a ficha de avaliação com escalas não estruturadas de $9 \mathrm{~cm}$ ancorados com termos de intensidade a $0,5 \mathrm{~cm}$ de cada extremidade.

Foram realizadas 12 sessões de treinamento utilizando-se amostras de referência indicadas pela equipe (Tabela 3) para cada atributo quanto aos aspectos qualitativo (reconhecimento do atributo) e quantitativo (medida da intensidade do atributo) (STONE; SIDEL, 2004).

Para comprovar o treinamento, os julgadores avaliaram as amostras de bebida de café Tradicional, Gourmet e Jacu, em cabines individuais, utilizando-se a ficha proposta. Empregouse o delineamento de blocos completos, e o teste foi repetido três vezes. Foram selecionados os julgadores que apresentaram boa discriminação, repetibilidade e consenso com os demais membros da equipe. Os dados de cada julgador em cada atributo foram submetidos à Análise de variância e ao teste F. O critério de seleção quanto à discriminação foi o valor de "p" de Famostra $\leq 0,5$ e para repetibilidade " $p$ " de Famostra $\geq 0,05$. O consenso de cada julgador com a equipe foi avaliado, em cada atributo, comparando-se a ordem de intensidade de cada amostra, fornecida pelo provador versus equipe. Dos 16 julgadores, foram selecionados 13 para compor a equipe final.

\section{TABELA 3 - DEFINIÇÕES E REFERÊNCIAS PARA OS TERMOS DESCRITORES LEVANTADOS PELOS JULGADORES}

\begin{tabular}{|c|c|}
\hline Descritores/ Definição & Amostras de referência \\
\hline \multicolumn{2}{|l|}{ Aparência } \\
\hline $\begin{array}{c}\text { Cor marrom: associada à intensidade do } \\
\text { grau de torra. }\end{array}$ & $\begin{array}{l}\text { Intensa: Melita Extra Forte } 35 \mathrm{~g} / 500 \mathrm{~mL} \text { de água } \\
\text { destilada. } \\
\text { Fraca: Jacu } 35 \mathrm{~g} / 500 \mathrm{~mL} \text { de água destilada. }\end{array}$ \\
\hline $\begin{array}{l}\text { Oleosa: associada à presença de } \\
\text { gotículas de óleo na superfície. }\end{array}$ & $\begin{array}{l}\text { Muito: Gourmet Iguaçu Liofilizado } 7 \mathrm{~g} / 100 \mathrm{~mL} \text { de } \\
\text { água destilada. } \\
\text { Pouco: Premium } 3 \text { Corações } 7 \mathrm{~g} / 100 \mathrm{~mL} \text { de água } \\
\text { destilada. }\end{array}$ \\
\hline $\begin{array}{l}\text { Translúcida: associada à passagem da } \\
\text { luz através da bebida de café. }\end{array}$ & $\begin{array}{l}\text { Muito: Melita Extra Forte } 35 \mathrm{~g} / 500 \mathrm{~mL} \text { de água } \\
\text { destilada. } \\
\text { Pouco: Café Solúvel Iguaçu Gourmet } 1 \mathrm{~g} / 100 \mathrm{~mL} \text { de } \\
\text { água destilada. }\end{array}$ \\
\hline \multicolumn{2}{|l|}{ Aroma } \\
\hline $\begin{array}{l}\text { Queimado: associado ao grau intenso de } \\
\text { torra. }\end{array}$ & $\begin{array}{l}\text { Intenso: Melita Extra Forte } 35 \mathrm{~g} / 500 \mathrm{~mL} \text { de água } \\
\text { destilada. } \\
\text { Fraco: Jacu } 35 \mathrm{~g} / 500 \mathrm{~mL} \text { de água destilada. }\end{array}$ \\
\hline \multicolumn{2}{|r|}{ 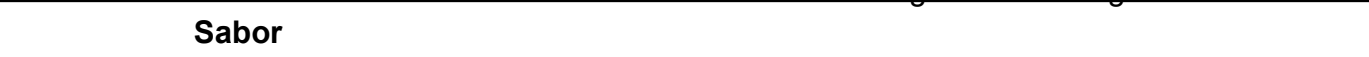 } \\
\hline $\begin{array}{l}\text { Queimado: sabor correspondente ao café } \\
\text { extremamente torrado. }\end{array}$ & $\begin{array}{l}\text { Intenso: Melita Extra Forte } 35 \mathrm{~g} / 500 \mathrm{~mL} \text { de água } \\
\text { destilada. } \\
\text { Fraco: Jacu } 35 \mathrm{~g} / 500 \mathrm{~mL} \text { de água destilada. }\end{array}$ \\
\hline $\begin{array}{c}\text { Gosto doce: caracterizado pela solução } \\
\text { de sacarose. }\end{array}$ & $\begin{array}{c}\text { Intenso: Civeta } 35 \mathrm{~g} / 500 \mathrm{~mL} \text { de água destilada. } \\
\text { Fraco: Melita Extra Forte } 35 \mathrm{~g} / 500 \mathrm{~mL} \text { de água } \\
\text { destilada. }\end{array}$ \\
\hline $\begin{array}{l}\text { Gosto ácido: caracterizado pela solução } \\
\text { de um ácido orgânico. }\end{array}$ & $\begin{array}{c}\text { Intenso: Tradicional } 3 \text { Corações } 35 \mathrm{~g}+0,1 \mathrm{~g} \text { de ácido } \\
\text { cítrico / } 500 \mathrm{~mL} \text { de água destilada. } \\
\text { Fraco: Tradicional } 3 \text { Corações } 15 \mathrm{~g} / 500 \mathrm{~mL} \text { de água } \\
\text { destilada. }\end{array}$ \\
\hline $\begin{array}{c}\text { Gosto amargo: caracterizado pela solução } \\
\text { de cafeína. }\end{array}$ & $\begin{array}{l}\text { Intenso: Melita Extra Forte } 35 \mathrm{~g} / 500 \mathrm{~mL} \text { de água } \\
\text { destilada. } \\
\text { Fraco: Gourmet } 3 \text { Corações } 20 \mathrm{~g} / 500 \mathrm{~mL} \text { de água } \\
\text { destilada. }\end{array}$ \\
\hline $\begin{array}{l}\text { Adstringente: sensação de "secura" na } \\
\text { boca. }\end{array}$ & $\begin{array}{c}\text { Intenso: Melita Extra Forte } 35 \mathrm{~g}+0,3 \mathrm{~g} \text { de ácido } \\
\text { tânico / } 500 \mathrm{~mL} \text { de água destilada. } \\
\text { Fraco: Melita Extra Forte } 20 \mathrm{~g} / 500 \mathrm{~mL} \text { de água } \\
\text { destilada. }\end{array}$ \\
\hline
\end{tabular}




\subsection{AVALIAÇÃO DAS BEBIDAS}

As cinco bebidas de café foram avaliadas pelos julgadores selecionados e treinados (equipe final), quanto aos atributos sensoriais levantados utilizando-se a ficha proposta, em cabines individuais de forma monódica (sequencialmente) de acordo com delineamento.

Após a prova, as bebidas não foram engolidas sendo descartadas em recipientes adequados.

\subsection{TESTE DE ACEITAÇÃO}

Para o teste sensorial de aceitação foram recrutados, via contato pessoal, 75 voluntários, para avaliar a aceitação global das bebidas por meio de teste de escala hedônica de nove pontos (1= desgostei muitíssimo; 5= nem gostei/nem desgostei; 9= gostei muitíssimo) (STONE; SIDEL, 2004).

\subsection{DELINEAMENTO EXPERIMENTAL E ANÁLISE ESTATÍSTICA DOS DADOS}

Os experimentos de caracterização físico-química das bebidas de cafés foram conduzidos de acordo com delineamento inteiramente casualizado e repetido três vezes. Foram realizadas três determinações em cada análise. Para as análises sensoriais o delineamento foi de blocos completos casualizados, sendo tratamentos, os cafés e blocos os julgadores. A análise descritiva quantitativa foi repetida três vezes.

Os dados obtidos foram submetidos a Análise de variância (ANOVA), teste $F$ de Snedecor, teste de $F$ ajustado, teste de comparação de médias de Tukey $(p \leq 0,05)(S A S, 2001)$ e análise de componentes principais.

\section{RESULTADOS E DISCUSSÃO}

\subsection{CARACTERIZAÇÃO FÍSICO-QUÍMICA DAS BEBIDAS}

Os valores de $\mathrm{pH}$ observados nas diferentes categorias de bebidas de café variaram de 4,86 (Gourmet) a 5,34 (Tradicional) (Tabela 4). $\mathrm{O}$ pH do café Civeta não diferiu do Premium (média de 5,16). Moura et al. (2007) relataram que quanto maior o percentual da espécie conilon no blend maior o $\mathrm{pH}$, esse comportamento foi observado neste trabalho, o café Tradicional que possui maior percentual da espécie conilon apresentou a bebida com o maior $\mathrm{pH}$ e o café Gourmet que é comercializado como $100 \%$ da espécie arábica, o menor valor.

\section{TABELA 4 ACIDEZ TITULÁVEL, PH E SÓLIDOS SOLÚVEIS TOTAIS DE BEBIDAS DE CAFÉ DE DIFERENTES CATEGORIAS ${ }^{1}$}

\begin{tabular}{llll}
\hline Qualidades & $\mathbf{p H}$ & Acidez titulável $^{*}$ & Sólidos solúveis $^{* *}$ \\
\hline Tradicional & $5,34 \pm 0,01^{\mathrm{a}}$ & $122,30 \pm 20,00^{\mathrm{c}}$ & $2,23 \pm 0,10^{\mathrm{a}}$ \\
\hline Premium & $5,17 \pm 0,03^{\mathrm{b}}$ & $145,60 \pm 20,03^{\mathrm{b}}$ & $2,10 \pm 0,07^{\mathrm{b}}$ \\
\hline Gourmet & $4,86 \pm 0,03^{\mathrm{d}}$ & $175,22 \pm 12,42^{\mathrm{a}}$ & $1,92 \pm 0,10^{\mathrm{c}}$ \\
\hline Jacu & $5,05 \pm 0,10^{\mathrm{c}}$ & $146,38 \pm 15,69^{\mathrm{b}}$ & $1,62 \pm 0,07^{\mathrm{d}}$ \\
\hline Civeta & $5,16 \pm 0,01^{\mathrm{b}}$ & $116,28 \pm 10,01^{\mathrm{c}}$ & $1,67 \pm 0,05^{\mathrm{d}}$ \\
\hline
\end{tabular}

${ }^{1}$ Valores médios de três repetições com três determinações cada \pm desvio-padrão.

Médias seguidas da mesma letra na coluna não diferem entre si, para cada componente, pelo teste de Tukey $(p \leq 0,05)$.

${ }^{*} \mathrm{~mL} \mathrm{NaOH} 0,1 \mathrm{~N} / 100 \mathrm{~g}$ amostra

${ }^{* *}$ Brix 
A acidez titulável variou de 116,28 (Civeta) a 175,22mL NaOH 0,1N/100g de amostra (Gourmet) (Tabela 4). Nesse aspecto, o café exótico Civeta também não diferiu do Tradicional nem o café Jacu do Premium (Tabela 4). Nos relatos da literatura (CLIFFORD, 1985; CLARKE, 1986; MENDES, 1999; MOURA et al., 2007) observa-se que quanto maior o percentual da espécie conilon no blend menor a acidez da bebida. Os cafés exóticos estudados eram $100 \%$ da espécie arábica, entretanto não obedeceram a essa premissa provavelmente devido ao seu "processamento" peculiar. Yate e Tuo (1995) ressaltam que o grau da torração é determinante da acidez; a bebida de café ligeiramente torrada apresenta uma acidez facilmente percebida pelo consumidor, enquanto a torração mais escura é pouco ácida. Os resultados obtidos neste estudo atendem a esta premissa. O pó torrado e moído do café Civeta (100\% da espécie arábica) apresentava o maior grau de torra dentre todas as amostras (Tabela 4). Os resultados de pH e acidez titulável estão coerentes com aqueles encontrados nos cafés torrados e moídos das mesmas categorias por Conti et al. (2013).

Os valores de sólidos solúveis situaram-se entre 1,62 (Jacu) e 2,23ํㅏix, (Tradicional) uma variação de aproximadamente $38 \%$, que pode ser explicada pela diferença de composição nos blends das variedades e diferentes graus de torra. Os dados demonstraram que quanto maior o percentual de conilon no blend maior o teor de sólidos solúveis na bebida, estando condizente com Moura et al. (2007).

\subsection{AVALIAÇÃO SENSORIAL DAS BEBIDAS}

\subsubsection{Análise descritiva quantitativa}

A análise do componente principal (ACP) dos dados da ADQ possibilitou a visualização das semelhanças e diferenças entre as amostras e permitiu identificar os atributos que mais contribuíram para a caracterização e diferenciação das bebidas. O primeiro componente apresentou autovalor de 7,154 e o segundo componente autovalor de 0,977 (próximo a 1), sendo utilizados para a interpretação dos resultados conforme o critério de Kaiser que estabelece a utilização de valores iguais ou maiores que 1 (LAWLESS; HEYMANN, 1998). O primeiro componente principal (CP1) explicou $79,49 \%$ da variabilidade total contida nas variáveis originais e o segundo (CP2) 10,86\%, totalizando $90,35 \%$ de explicação.

Os valores de correlações dos vetores (atributos) com os eixos (componentes principais) indicam a importância de cada atributo em cada componente (Tabela 5). Considerando correlação superior a 0,7 (em valores absolutos) e em ordem decrescente de contribuição discriminante, os atributos "gosto doce" e "transparência" (correlação positiva), "gosto amargo", "aroma" e sabor "queimado", "cor marrom", "adstringência" e aparência "oleosa" (correlação negativa) foram importantes para o CP1; apenas "gosto ácido" teve correlação negativa com o CP2.

\section{TABELA 5 VALORES DE CORRELAÇÃO DOS ATRIBUTOS COM OS EIXOS CP1 E CP2}

\begin{tabular}{ccc}
\hline Atributos & CP1 & CP2 \\
\hline Cor marrom & $-0,935^{*}$ & 0,190 \\
\hline Transparência & $0,933^{*}$ & $-0,161$ \\
\hline Oleosa & $-0,794^{*}$ & $-0,439$ \\
\hline Aroma Queimado & $-0,976^{*}$ & $-0,009$ \\
\hline Sabor Queimado & $-0,964^{*}$ & $-0,041$ \\
\hline Gosto doce & $0,943^{*}$ & 0,108 \\
\hline Gosto ácido & 0,518 & $-0,815^{*}$ \\
\hline Gosto amargo & $-0,984^{*}$ & $-0,002$ \\
\hline Adstringência & $-0,878^{*}$ & $-0,187$ \\
\hline
\end{tabular}

\footnotetext{
* Correlações $\geq|0,7|$.
} 
As representações gráficas do plano $\mathrm{CP} 1 \times \mathrm{CP} 2$ dos dados sensoriais estão descritos nas figuras 1 e 2 . Vetores próximos (Figura 1 ) indicam correlação positiva entre eles; posicionados em um ângulo de $180^{\circ}$, correlação negativa, e quando são ortogonais não há correlação linear entre eles. As mais importantes e significativas correlações estão comentadas a seguir, a partir das análises de correlação de Pearson e teste t (Tabela 6).

TABELA 6 MATRIZ DE CORRELAÇÃO ENTRE OS DESCRITORES PARA AS CINCO BEBIDAS AVALIADAS

\begin{tabular}{|c|c|c|c|c|c|c|c|c|c|}
\hline Atributos & $\begin{array}{c}\text { Cor } \\
\text { Marrom }\end{array}$ & Transp. & Oleosa & A. Quim. & $\begin{array}{c}\text { S. } \\
\text { QueiM }\end{array}$ & $\begin{array}{c}\text { G. } \\
\text { Doce }\end{array}$ & G Ácido & $\begin{array}{c}\text { G. } \\
\text { Amargo }\end{array}$ & Adstr \\
\hline $\begin{array}{l}\text { Cor } \\
\text { Marrom }\end{array}$ & 1,000 & & & & & & & & \\
\hline Transp. & $-0,939$ & 1,000 & & & & & & & \\
\hline Oleosa & $-0,662$ & $-0,662$ & 1,000 & & & & & & \\
\hline
\end{tabular}

\section{Aroma}
A.
$0,898 \quad-0,903$
$0,799 \quad 1,000$

Sabor
S.
Queim.
0,84
$-0,874$
0,692
0,945
1,000

\begin{tabular}{lllllllll}
\hline $\begin{array}{l}\text { G. } \\
\text { Doce }\end{array}$ & $-0,829$ & 0,865 & $-0,752$ & $-0,900$ & $-0,958$ & 1,000 & & \\
\hline $\begin{array}{l}\text { G. } \\
\text { Ácido }\end{array}$ & $-0,605$ & 0,559 & $-0,128$ & $-0,413$ & $-0,446$ & 0,384 & 1,000 & \\
\hline G. & 0,908 & $-0,921$ & 0,768 & 0,960 & 0,959 & $-0,940$ & $-0,497$ & 1,000 \\
Amarg. & 0,753 & $-0,690$ & 0,754 & 0,875 & 0,880 & $-0,799$ & $-0,355$ & 0,832 \\
\hline \\
Adstr.
\end{tabular}

Resultados em negrito apresentam correlação significativa a $p \leq 0,05$ (teste $t$ ).

Atributos sensorials: Cor marrom; Transp.: transparência; Oleosa; A. queim.: aroma queimado; $S$. queim.: sabor queimado; G. doce: gosto doce; G. ácido: gosto ácido; G. amarg.: gosto amargo e Adstr.: adstringência.

A cor marrom teve uma correlação positiva $(r=0,908)$ com o gosto amargo, ou seja, amostra mais marrom apresentou maior intensidade de gosto amargo. Esse comportamento também foi observado entre o sabor e o aroma queimado e gosto amargo.

Com relação à aparência, o atributo transparência apresentou correlação negativa com a cor marrom $(-0,939)$, gosto amargo $(-0,921)$, aroma queimado $(-0,903)$ e sabor queimado $(-0,874)$. Portanto, amostra com maior transparência mostrou menor intensidade de gosto amargo, aroma e sabor queimado. $O$ gosto ácido não se correlacionou com nenhum atributo. 


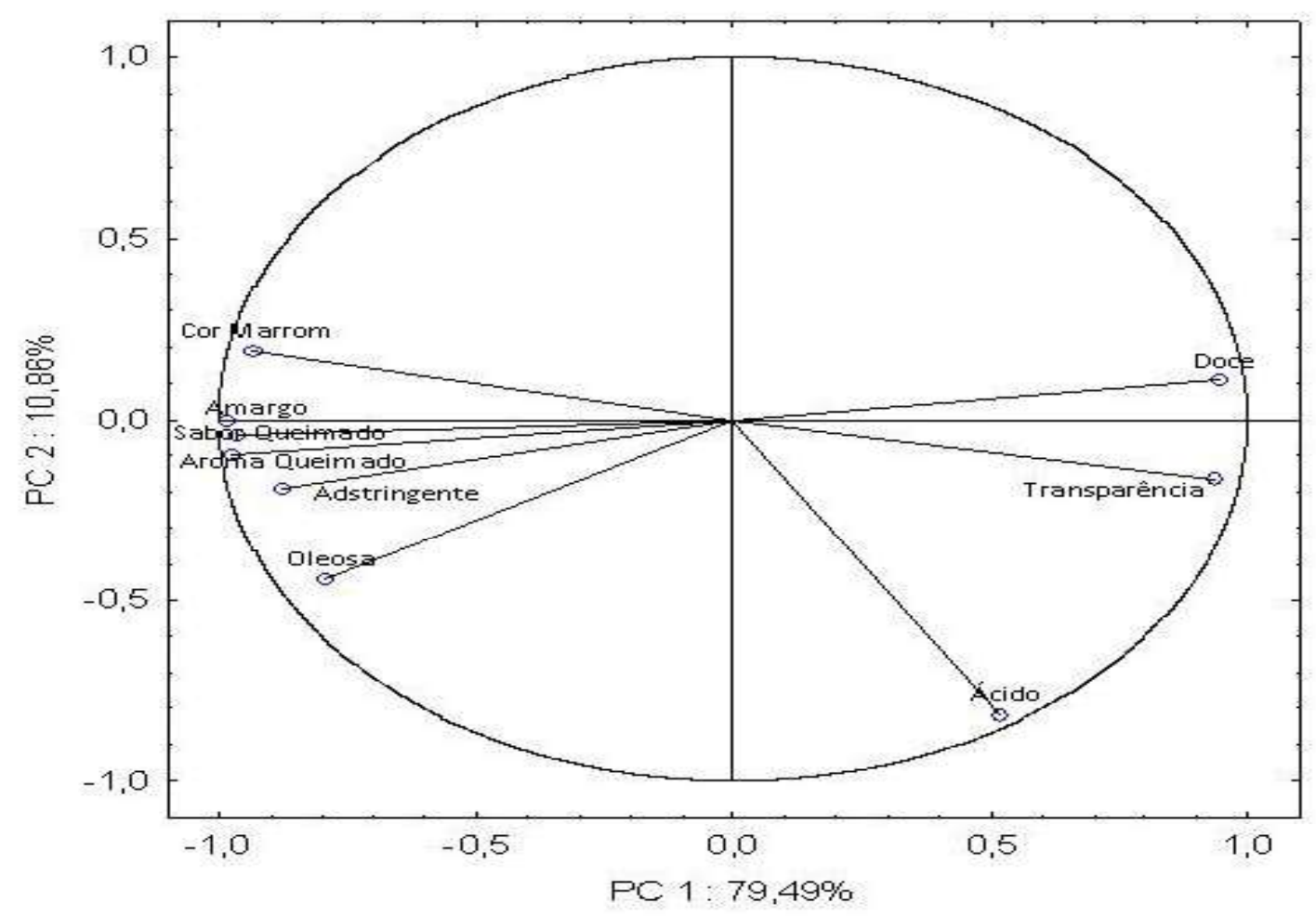

FIGURA 1. PROJEÇÕES DOS ATRIBUTOS SENSORIAIS

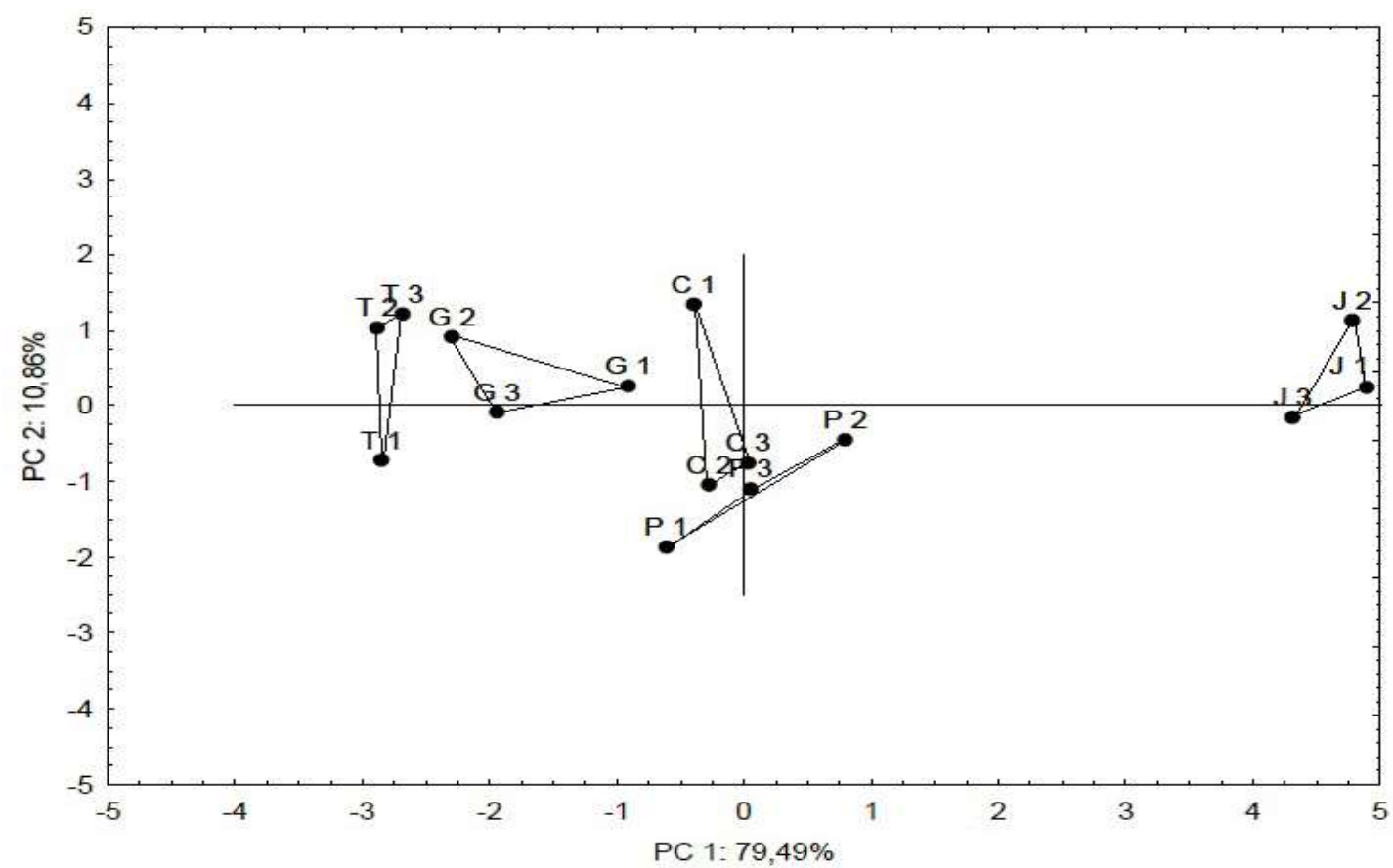

FIGURA 2. CATEGORIAS DE BEBIDA DE CAFÉ SOBRE O PLANO FATORIAL (CP1 X CP2)

*Categorias e repetições T1, T2, T3: Tradicional; P1, P2, P3: Premium; G1, G2, G3: Gourmet; J1, J2, J3: Jacu; C1, C2, C3: Civeta. 
Na Figura 2, cada categoria de bebida de café está representada por um triângulo, no qual cada vértice corresponde ao valor médio atribuído pela equipe em cada repetição da avaliação. Os vértices próximos indicam boa repetibilidade da avaliação, que foi observada para os cafés Premium, Gourmet e Jacu.

A CP1 discriminou as bebidas quanto ao grau de torra dos grãos de café. O café Jacu, à direita, com grau de torra clara e os cafés Tradicional, Gourmet, Premium e Civeta, mais à esquerda, eram de torra média e escura. A CP2 mostrou uma tendência de separação quanto à acidez, indicando que o café Premium mais abaixo no plano como mais ácido.

Na Figura 2, verifica-se que as bebidas de café Tradicional e Gourmet estão próximas, portanto são semelhantes e com características opostas ao café Jacu que está localizado a $180^{\circ} \mathrm{em}$ relação a essas amostras. As bebidas Premium e Civeta, por estarem próximas à região central do plano, provavelmente possuem intensidade intermediária para os atributos avaliados. Analisando-se as figuras 1 e 2 em conjunto, verifica-se que a bebida do café Jacu foi descrita como sendo a mais doce e de maior transparência, as bebidas Tradicional e Gourmet mostraram maior intensidade dos atributos cor marrom, sabor amargo, aroma e gosto queimado e adstringência. Os cafés Premium e Civeta não apresentaram características marcantes, apresentando intensidades intermediárias.

A análise dos dados por ANOVA e teste de comparação de médias de Tukey (Tabela 7) confirmaram as indicações da ACP quanto à caracterização sensorial das bebidas de café. De acordo com os resultados, verificou-se que houve diferença $(p \leq 0,05)$ entre as bebidas para todos os atributos, exceto para o gosto ácido, cuja intensidade em cada amostra não foi diferenciada pela equipe sensorial, estando em desacordo com valores de $\mathrm{pH}$ e acidez titulável (Tabela 4).

\section{TABELA 7 MÉDIA DOS ATRIBUTOS SENSORIAIS DAS BEBIDAS DE CAFÉ OBTIDAS NA ANÁLISE DESCRITIVA QUANTITATIVA ${ }^{1}$}

\begin{tabular}{llllll}
\hline Atributos & Tradicional & Premium & Gourmet & Jacu & Civeta \\
\hline Aparência & & & & \\
\hline Cor marrom & $7,31 \pm 0,76^{\mathrm{a}}$ & $5,94 \pm 1,19^{\mathrm{b}}$ & $6,96 \pm 0,95^{\mathrm{a}}$ & $4,48 \pm 1,71^{\mathrm{c}}$ & $6,44 \pm 1,93^{\mathrm{ab}}$ \\
\hline Oleosa & $4,62 \pm 1,94^{\mathrm{a}}$ & $4,74 \pm 2,14^{\mathrm{a}}$ & $4,76 \pm 2,04^{\mathrm{a}}$ & $2,54 \pm 1,74^{\mathrm{b}}$ & $4,83 \pm 2,22^{\mathrm{a}}$ \\
\hline Transparência & $3,30 \pm 2,51^{\mathrm{c}}$ & $4,75 \pm 2,12^{\mathrm{b}}$ & $3,47 \pm 2,35^{\mathrm{bc}}$ & $6,18 \pm 1,89^{\mathrm{a}}$ & $4,67 \pm 2,38^{\mathrm{b}}$ \\
\hline Aroma & & & & & \\
\hline Queimado & $6,01 \pm 1,72^{\mathrm{a}}$ & $5,04 \pm 2,02^{\mathrm{a}}$ & $5,46 \pm 1,85^{\mathrm{a}}$ & $2,71 \pm 1,47^{\mathrm{b}}$ & $4,74 \pm 2,16^{\mathrm{a}}$ \\
\hline Sabor & & & & & \\
\hline Queimado & $6,93 \pm 1,29^{\mathrm{a}}$ & $5,45 \pm 2,00^{\mathrm{b}}$ & $6,17 \pm 1,85^{\mathrm{a}}$ & $3,40 \pm 2,02^{\mathrm{c}}$ & $5,20 \pm 2,10^{\mathrm{b}}$ \\
\hline Gosto doce & $1,82 \pm 1,57^{\mathrm{b}}$ & $3,01 \pm 2,11^{\mathrm{b}}$ & $2,32 \pm 1,93^{\mathrm{b}}$ & $5,07 \pm 2,21^{\mathrm{a}}$ & $3,15 \pm 2,14^{\mathrm{b}}$ \\
\hline Gosto ácido & $3,81 \pm 2,12^{\mathrm{a}}$ & $5,08 \pm 2,14^{\mathrm{a}}$ & $4,02 \pm 2,26^{\mathrm{a}}$ & $4,87 \pm 2,05^{\mathrm{a}}$ & $4,32 \pm 2,33^{\mathrm{a}}$ \\
\hline Gosto amargo & $7,09 \pm 1,08^{\mathrm{a}}$ & $5,31 \pm 1,96^{\mathrm{b}}$ & $6,54 \pm 1,51^{\mathrm{ab}}$ & $3,01 \pm 1,97^{\mathrm{c}}$ & $5,50 \pm 2,06^{\mathrm{b}}$ \\
\hline Adstringente & $5,27 \pm 2,10^{\mathrm{a}}$ & $4,94 \pm 1,77^{\mathrm{ab}}$ & $4,84 \pm 1,88^{\mathrm{ab}}$ & $3,84 \pm 2,02^{\mathrm{b}}$ & $4,97 \pm 2,05^{\mathrm{ab}}$ \\
\hline
\end{tabular}

Valores médios de 13 julgadores \pm desvio-padrão.

${ }^{1}$ Médias na mesma linha acompanhadas de letras minúsculas iguais não diferem de $p \leq 0,05$. Escala de $9 \mathrm{~cm}$. 
As bebidas de café Tradicional e Gourmet mostraram cor marrom mais intensa que Premium e Jacu. O escurecimento do grão de café ocorre devido à formação de melanoidinas, durante o processo de torra a partir da reação de Maillard entre açúcares redutores e aminoácidos presentes no grão que contribui para a coloração marrom na bebida (LÓPEZ-GALILEA et al., 2007; BORELLI et al., 2002; DELGADO-ANDRADE et al., 2005). Estudos realizados por Conti et al. (2013) com diferentes categorias de café (Tradicional, Premium, Gourmet) e cafés exóticos (Jacu e Civeta) torrados e moídos indicaram que dentre os cafés estudados, o Civeta e Jacu apresentaram os menores e maiores valores dos parâmetros cor $\left(L^{*}, h^{*}, C^{*}\right)$ respectivamente, indicando que o café Civeta provavelmente foi submetido a um maior grau de torra, sendo mais escuro, mais avermelhado, menos amarelo e com cor menos pura, e o Jacu a um menor grau de torra, sendo mais claro e mais amarelado. A percepção sensorial da cor nas bebidas (Tabela 7) está condizente com tal estudo e com as informações sobre o grau de torra apresentado na embalagem (Tabela 4).

A bebida de café Jacu mostrou a aparência menos oleosa $(2,54)$, e as demais bebidas não diferiram entre si (média de 4,74). O grau de torra mais clara do café Jacu pode justificar esse resultado, pois em grau de torra mais escuro, muitas células sofrem rompimento e o óleo pode migrar para a superfície do grão (FRANÇA et al., 2001; NASCIMENTO et al., 2007) e ser transferido para a bebida. Em estudos preliminares Conti et al. (2013) verificaram que o teor de lipídios nos cafés torrados e moídos Tradicional, Premium, Gourmet e Civeta era superior ao presente no café Jacu.

Em relação à transparência da bebida, o café Jacu obteve o maior valor $(6,18)$, e o Tradicional e Gourmet obtiveram menores valores (média de 3,38). O teor de sólidos solúveis na bebida (Tabela 4) pode estar associado a esse atributo sensorial. O café Jacu, mais transparente, foi o que continha menor teor de sólidos solúveis $\left(1,62^{\circ}\right.$ Brix $)$ e o Tradicional, menos transparente, o maior teor de sólidos solúveis $\left(2,23^{\circ} \mathrm{Brix}\right)$. O teor de sólidos solúveis na bebida normalmente está associado ao "corpo" (PINTO et al., 2011; MENDONÇA et al., 2005), porém esse atributo não foi levantado pela equipe sensorial. Pode-se relacionar o "corpo" à transparência, em que a bebida mais transparente (Jacu) seria menos encorpada, e a menos transparente (Tradicional) a mais encorpada.

Observou-se, também, que a bebida Jacu apresentou menor aroma de queimado $(2,71)$, provavelmente por ter os grãos menos torrados (Tabela 4), tendo em vista que os compostos voláteis, responsáveis pelo aroma característico da bebida, são produzidos durante o processo de torra do grão de café cru. As demais amostras não foram diferentes em relação a esse atributo (média de 5,31).

Em relação ao atributo sabor, exceto o gosto ácido, a bebida de café Jacu destacou por apresentar as menores intensidades de sabor queimado $(3,40)$, gosto amargo $(3,01)$ e adstringência $(3,84)$ e maior doçura $(5,07)$, comportamento muito oposto ao observado para as bebidas de café Tradicional e Gourmet.

O grau de torra afeta diretamente o aroma e sabor da bebida de café por definir os vários compostos que são formados no processo e que são extraídos durante o preparo da bebida. No processo, os açúcares (SHANKARAYANA et al., 1974) e os polissacarídeos (DE MARIA et al., 1994) geram os furanos que são caracterizados pelos aromas de caramelo e de açúcar queimado. Os pirróis podem ser formados a partir da degradação dos açúcares ou da trigonelina (HWANG et al., 1995). Dentre os pirróis destaca-se o alqui-pirróis que em baixa concentração produz aroma doce e levemente queimado (SHIGEMATSU et al., 1972). As piridinas podem ser geradas da mesma forma que os pirróis (SIVETZ; DESROSIER, 1979; VIANI; HORMAN, 1974; LIEN; NAWAR, 1974; KATO et al., 1973), em específico o composto 2-metil-piridina que fornece um aroma relacionado ao de matéria queimada e a sensação adstringente (MAGA, 1981), essa característica aromática também está relacionada com os compostos fenólicos voláteis (DART; NURSTEN, 1985). Os ácidos clorogênicos são progressivamente hidrolisados a ácidos cafeico e quínico, contribuindo amplamente para a formação do aroma e sabor final da bebida cujos sabores são mais amargos e adstringentes (FERNANDES et al., 2001; CLIFFORD, 1985; DART; NURSTEN, 1985). Enquanto 
a cafeína contribui apenas com $10 \%$ no amargor da bebida (ILLY; VIANI, 1996; SALVA; LIMA, 2007). Também se observa que a intensidade do sabor amargo é mais perceptível na bebida de café conilon quando comparado à bebida de café arábica (RIBEYRE, 2003; DELLA LUCIA, 2011; MOURA et al., 2007).

A cor do grão torrado, associada ao grau de torra, pode indicar o aroma e sabor da bebida. Em grãos muito escuros pode ter ocorrido carbonização de alguns componentes, portanto, acentuando o aroma e sabor de queimado na bebida (MELLO, 2004).

A auto-oxidação de lipídios está relacionada à produção de cetonas (DART; NURSTEN, 1985), e as cetonas cíclicas (maltol e cicloteno) apresentam odores que podem ser associados ao açúcar queimado (VARNAM; SUTHERLAND, 1997).

As resoluções no 19, 30 e 31 da Secretaria da Agricultura e Abastecimento do Estado de São Paulo - SAASP (2007a, 2007b, 2010) por meio das Normas de Padrões Mínimos de Qualidade para Café Torrado em Grão e Torrado e Moído - Característica Especial: Café Tradicional, Premium e Gourmet respectivamente, definem a classificação da bebida do café Tradicional que deve variar entre bebida mole a rio, excluindo-se o gosto riozona; do café Premium dura ou mole e do café Gourmet apenas mole ou estritamente mole. Monteiro (2005) observou que o grau de torra (claro, médio e escuro) interferiu em maior intensidade no perfil sensorial das bebidas que as classes (mole, dura ou rio). As bebidas com torra escura apresentaram maior intensidade nos atributos cor, aroma e sabor queimado, gosto amargo e adstringência. Ao analisar a preferência dos consumidores observou-se que a menor aceitação foi da bebida rio com grau de torra escuro em relação à mole e dura com mesmo grau de torra. Junqueira et al. (2011) observaram que quanto melhor o café, maior sua acidez e menor seu amargor, e descrevem, conforme o perfil sensorial, a bebida de café Tradicional como rústica, de maior amargor e menor acidez, apresentando a mesma tendência das bebidas avaliadas neste estudo.

Tendo como base tais informações, observou-se que a descrição sensorial obtida para as bebidas de café estão condizentes com os valores das análises químicas (lipídios, carboidratos, compostos fenólicos totais, ácido clorogênico total, cafeína, trigonelina, ácido nicotínico, açúcares redutores, açúcares totais e açúcares não redutores) e físicas (cor do pó) realizadas por Conti et al. (2013) em cafés torrado e moído das mesmas amostras.

\subsection{ACEITABILIDADE}

As notas médias de aceitação das bebidas de café encontraram-se entre 5,60 a 6,53 indicando aceitação moderada (Tabela 8). Notou-se diferença de aceitação somente entre a bebida do café Civeta (mais aceita) e a do café Gourmet (menos aceita).

\section{TABELA 8 ACEITAÇÃO SENSORIAL DAS BEBIDAS DE CAFÉ DE DIFERENTES CATEGORIAS}

\begin{tabular}{cc}
\hline Categoria & Valor hedônico \\
\hline Tradicional & $6,3^{\mathrm{ab}}$ \\
\hline Premium & $6,0^{\mathrm{ab}}$ \\
\hline Gourmet & $5,6^{\mathrm{b}}$ \\
\hline Jacu & $6,0^{\mathrm{ab}}$ \\
\hline Civeta & $6,5^{\mathrm{a}}$ \\
\hline
\end{tabular}

1: desgostei muitíssimo; 5: nem gostei/nem desgostei, 9: gostei muitíssimo.

Valores médios de 76 consumidores.

Médias na mesma linha acompanhadas de letras minúsculas iguais não diferem de p $\leq 0,05$. Escala de $9 \mathrm{~cm}$. 


\section{CONCLUSÃO}

Considerando os resultados apresentados e tendo em vista que o grau de torra dos grãos é mais crítico que a categoria do café (Tradicional, Premium, Gourmet, Jacu e Civeta) para as características sensoriais da bebida, é possível concluir que:

A bebida de café Jacu de torra clara apresenta características sensoriais mais suaves, exceto doçura que é mais intensa.

O café Civeta, por sua vez, caracteriza-se por apresentar intensidades intermediárias de atributos sensoriais, e que são mais apreciadas pelos consumidores.

Já a bebida de café Tradicional possui características sensoriais marcantes e intensas, exceto quanto ao gosto doce.

O perfil sensorial do café Gourmet se assemelha mais ao da bebida de café Tradicional. O café Gourmet é menos apreciado que o Civeta, porém tal fato não ocorre com o Tradicional. E a bebida Premium é semelhante ao Civeta e com igual aceitação.

\section{ABSTRACT}

\section{SENSORY CHARACTERIZATION, PHYSICOCHEMICAL AND ACCEPTANCE OF EXOTIC COFFEE DRINKS AND DIFFERENT CATEGORIESCOMMERCIAL BRAZILIAN}

Considering the introduction of coffees denominated exotic in the market also its potential for consumption growth, the aim of this study was to determine the sensory profile, physicochemical and accepting exotic coffees beverages (Jacu and Civeta) and brazilian categories (Traditional, Premium and Gourmet). The $\mathrm{pH}$, titratable acidity, soluble solids, sensory profile and acceptance were determinated. Data were treated by analysis of variance (ANOVA), Tukey test and Principal Components Analysis. The $\mathrm{pH}$ ranged from 4.86 (Gourmet) to 5.34 (Traditional), of $116.28 \mathrm{~mL}$ (Civet) to $175.22 \mathrm{NaOH} 0.1 \mathrm{~N} / 100 \mathrm{~g}$ sample (Gourmet) and soluble solids of 1.62 (Jacu) to $2.23^{\circ}$ Brix (Traditional). The sensory profile was determined by Quantitative Descriptive Analysis of 13 selected and trained panelists. Nine attributes were evaluated; brown, oily appearance, translucent, smell of burning, burnt flavor, sweet, sour, bitter and astringent feeling. Of these, the acid taste was not important for discrimination of coffees. The coffee beverage Jacu is distinguished from other sensory characteristics by presenting less intense, except for sweetness. Civet Coffee intermediate intensities presented in sensory attributes and showed greater acceptance (6.5) that the Gourmet Coffee (6.0) when evaluated by 75 consumers and a nine-point hedonic scale.

KEYWORDS: CIVETA; GUAN; EXOTIC COFFEES; SENSORY.

\section{REFERÊNCIAS}

1 ABIC - Associação Brasileira da Indústria do Café. Programas ABIC. Disponível em: <http://www.abic.com.br>. Acesso em: 05 de outubro de 2010.

2 ABIC - Associação Brasileira da Indústria do Café. Normas de Qualidade Recomendável e Boas Práticas de Fabricação de Cafés Torrados e Moídos, 2008. Disponível em: <http://www.abic.com.br/arquivos/ccq_norma_out07. pdf>. Acesso em: 03 de junho de 2009.

3 ABIC. Associação Brasileira da Indústria do Café. Indicadores da Indústria do Café. Disponível em: <http://www.abic. com.br>. Acesso em: 06 de julho de 2011.

4 AOAC. Association of Official Analytical Chemists. Official methods of analysis of AOAC International. $15^{\text {th }}$ ed. Arlington, 1990. 
5 BORRELLI, R.C., VISCONTI, A., MENNELLA, C., ANESE, M.; FOGLIANO, V. Chemical characterization and antioxidant properties of coffee melanoidins. Journal of Agriculture and Food Chemistry; v.50, n.22, p.6527-6533, 2002.

6 BUENAVENTURA-SERRANO, C.E.; CASTAÑO-CASTRILLÓN, J.J. Influencia de la altitud em la calidad de la bebida de muestras de café procedente del ecotopo 206B em Colombia. Cenicafé, v.53, n.2, p. 119-131, 2002.

7 BRASIL. Ministério da Agricultura. Produção de café conilon. Disponível em:<http://webcache.googleusercontent. com/search?q=cache:ZrMKqYiKwckJ:softwaresesistemas.com.br/agricultura/producao-de-cafe-conilon-de-qualidade/+ sin\%C3\%B4nimos+conilon+e+robusta\&hl=pt-BR\&gl=br\&strip=1>. Acesso em: 02 de julho de 2013.

8 CAFEMERCADO. Disponível em: <http://cafemercado.com.br/lojavirtual>. Acesso em: 05 de julho de 2011

9 CAMOCIM. Estate Grown Products. Disponível em: <http://www.camocimorganic.com/>. Acesso em: 14 de julho de 2009.

10 CLARKE, R.J. The flavor of coffee. In: MORTON, I.D.; MACLEOD, A.J. Food Flavors: Part B. The flavours of beverages. Amsterdam: Ed. Elsevier Science Publ., 1986.

11 CLARKE, R.J.; MACRAE R. Coffee. Vol. 1 Chemistry, Elsevier, London, 1985.

12 CLIFFORD, M. N. Chlorogenic acids. In: CLARKE, R. J.; MACRAE, R. Coffee. v.1: Chemistry (p. 153-202). London: Elsevier Applied Science, 1985.

13 CONTI, M.C.M.D; KITZBERGER, C.S.G; SCHOLZ, M.B.S; PRUDENCIO, S.H. Caracterização física e química de cafés torrados e moídos exóticos e de diferentes categorias brasileiras comerciais. Boletim do Centro de Pesquisa de Processamento de Alimentos, Curitiba, v. 31, n. 1, jan./jun. 2013

14 CUNHA, Neísa. CafÃ@ 3 CoraÃ§̃̃ $\mu e s$ - Contato Site [mensagem pessoal]. Mensagem recebida por <marycarmen@ bol.com.br> em 28 ago. 2011.

15 DART, S. K.; NURSTEN, H. E. In Coffee Chemistry (vol. 1); Clarke, R. J.; Macrae, R., Eds.; Elsevier Applied Science Publishers; London, 1985; p. 223.

16 DE MARIA, C. A. B.; TRUGO, L. C.; AQUINO NETO, F. R.; MOREIRA, R. F. A. Arabinogalactan as a potential furfural precursor in roasted coffee. International Journal of Food Science \& Technology, v.29, n.5, p. 559, 1994.

17 DELGADO-ANDRADE, C.; MORALES, F. J. Unraveling the contribution of melanoidins to the antioxidant activity of coffee brews. Journal of Agriculture and Food Chemistry, v.53, p. 1403- 1407, 2005.

18 DELLA-LUCIA, S.M; LIMAFILHO, T.; SARAIVAS.H.; CARNEIRO, J.C.S.; ROBERTO, C.D. Perfil sensorial e aceitabilidade de bebidas de café tipo espresso preparadas a partir de blends de café arábica e conilon. ENCICLOPEDIA BIOSFERA, Centro Cientifico Conhecer - Goiânia, vol.7, n.12; 2011

19 FERNANDES, S.M; PINTO, N.A.V.D.; THÉ, P.M.P.; PEREIRA, R.G.F.A; CARVALHO, V.D.de. Teores de Polifenóis, Ácido Clorogênico, Cafeína e Proteína em Café Torrado. Revista Brasileira de Agrociência, v.7, n 3, p.197-199, 2001

20 FRANÇA, A. S.; OLIVEIRA, L.S.; BORGES, M.L.A.; VITORINO, M.D. Evolução da composição do extrato aquoso de café durante o processo de torrefação. Revista Brasileira de Armazenamento, Especial café, n.2, p.37-47, 2001.

21 HWANG, H-ING.; HARTMAN, T. G.; HO C-TANG. Relative reactivities of amino acids in the formation of pyridines, pyrroles and oxazoles. Journal of Agriculture and Food Chemistry, v.43, p.2917, 1995.

22 ICO - International Coffee Organization. Aspectos botânicos. Disponível em: <http://www.ico.org/pt/botanical_p. asp?section=Sobre_o_café>. Acesso em: 13 de julho de 2009.

23 ILLY, A.; VIANI, R. Espresso Coffee: The chemistry of quality. 2.ed. San Diego: Academic press, 1996, 253p

24 INTERNATIONAL ORGANIZATION FOR STANDARDIZATION. ISO 3972: Sensory analysis: method of investigating sensitivity of taste. Switzerland, 1991.

25 JUNQUEIRA, N.M.D.; GARCIA, A.O.; ANSELMO, C.A.F. Estudo do hábito de consumo da bebida do café e a Importância da informação sobre sua qualidade global (Tradicional, Superior e Gourmet). Disponível: <http://www. cnpm.embrapa.br/5ciic/anais/Artigos/RE11224.pdf.> Acesso em: 24 de outubro de 2011.

26 KATO, S.; KURATA, T.; FUJIMAKI, M. Volatile compounds produced by the reaction of L-cystein or L-cystine with carbonyl compounds. Agricultural Biology and Chemistry, v. 37, p. 539- 544, 1973.

27 KOBAYASHI, M.L.; BENASSI, M.T. Caracterização sensorial de cafés solúveis comerciais por Perfil Flash. Semina: Ciências Agrárias, Londrina, v.33, suplemento 2, p.3081-3092, 2012.

28 LAWLESS, H. T.; HEYMANN, H. Sensory evaluation of food: principles and practices. New York: Chapman \& Hall, 1998.

29 LIEN, Y. C.; NAWAR, W. W. Thermal decomposition of some amino acids. Valine, Leucine and Isoleucine. Journal of Food Science, v. 39, n.5, p. 911-913, 1974. 
30 LÓPEZ-GALILEA, I.; PAZ DE PEÑA, M. Correlation of selected constituents with the total antioxidant capacity of coffee beverages: influence of the brewing procedure. Journal of Agriculture and Food Chemistry, v.55, p. 6110-6117, 2007.

31 MAGA, J.A.; Pyrroles in food. Journal of Agriculture and Food Chemistry, v.29, p.691-694, 1981.

32 MARCONE, M.F. Composition and properties of Indonesian palm civet coffee (Kopi Luwak) and Ethiopian civet coffee. Food Research International, v.37, p.901 912, 2004.

33 MELLO, W. L. B. A importância da informação sobre do grau de torra do café e sua influência nas características organolépticas da bebida. Comunicado técnico 28 - EMBRAPA São Carlos, SP, 2004

34 MENDES, L.C. Otimização do processo de torração do café robusta (Coffea canephora Conillon) para formulação de blends com café arábica (Coffea arabica). 1999. 101p. Dissertação (Mestrado em Tecnologia de Alimentos), Universidade Estadual de Campinas.

35 MENDONÇA, L.M.V.L.; PEREIRA, R.G.F.A.; MENDES, A.N.G. Parâmetros bromatológicos de grãos crus e torrados de cultivares de café (Coffea arabica L.). Ciência e Tecnologia de Alimentos, v. 25, n. 2, p.239-243, 2005.

36 MONTEIRO, M.A.M. Caracterização sensorial da bebida de café (coffea arábica L.): análise descritiva quantitativa, análise tempo-intensidade e testes afetivos. 2002. 157p. Tese (Doutorado em Ciência e Tecnologia de Alimentos), Universidade Federal de Viçosa.

37 MORAES, P.C.B.T. O impacto do uso de edulcorantes em bebidas de café solúvel e café torrado/moido como substituidos da sacarose. 2008. 129f. Tese (Doutorado em Nutrição), Universidade Estadual de Campinas.

38 MORELI, A.P. Café - Histórico, variedades e mercados. Universidade do Espírito Santo - Centro de Ciências Agrárias. Tecnologia de Pós-Colheita. Disponível em: <http://www.agais.com/tpc/capitulo.php.> Acesso em: 03 de agosto de 2009.

39 MOSKOWITZ, H. R. The dollar value of product quality: the effect of pricing versus overall liking on consumer stated purchase intent for pizza. Journal of Sensory Studies, v.10, n.3, p.239-247, 1995

40 MOURA, S.C.R.; GERMER, S.P.M; ANJOS, V.D.A.; MORI, E.E.M.; MATTOSO, L.H.C.; FIRMINO, A.; NASCIMENTO, C.J.F. Avaliações físicas, químicas e sensoriais de blends de café arábica com café canephora (robusta). Brazilian Journal of Food Technology, Campinas, v.10, n.4, p. 271 -277, out./dez., 2007

41 NASCIMENTO, E.A; AQUINO, F.J.T; NASCIMENTO, P.M.; CHANG, R.; MORAIS, S.A.L. Composição química do café conilon em diferentes torração. Ciência \& Engenharia, v.16, n. 1/2, p. 17 - 21, jan - dez. 2007

42 PINTO, N.A.V.D.; FERNANDES, S.M.; GIRANDA, R.N.; PEREIRA, R.G.F.A.; CARVALHO, V.D. Avaliação de componentes químicos de padrões de bebida para preparo do café expresso. Ciência e Agrotecnologia, Lavras, v.26, n.4, p.826-829, 2002.

43 RIBEYRE, F. Reconocimiento de Calidades de Robusta In: SIMPÓSIO INTERNACIONAL SOBRE QUALIDADE DE CAFÉ, 1, 2003, Campinas. Palestras... Campinas, SP: IAC - INSTITUTO AGRONÔMICO DE CAMPINAS, 2003. Disponível em: <www.iac.sp.gov.br>. Acesso em: 16 de junho de 2010.

44 RONCHI, P.R. A origem do café conilon. Disponível em: <http://www.cetcaf.com.br/informacoes\%20gerais/origem\%20 cafe\%20conilon/origem_cafe_conilon.htm.> Acesso em: 06 de julho de 2011.

45 SALVA, T.J.G.; LIMA, V.B. A composição química do café e as características da bebida e do grão. O Agronômico, Campinas, v.59, n.1, p. 57-59, 2007.

46 SANTOS, A.C.A. O café de jacu. Disponível em: <http://66.228.120.252/artigos/1577810>. Acessso em: 14 de maio de 2011.

47 SAS INSTITUTE. SAS user's guide: statistics. Version 8.2. Cary, 2001.

48 SCHOENHOLF, D. N. Kopi Luwak: The stercoaceous coffee of indonesia. Tea and Coffee Trade Journal, p.142-146, 1999.

49 SECRETARIA DE AGRICULTURA, IRRIGAÇÃO E REFORMAAGRÁRIA - SEAGRI. Cultura - Café Conilon. Disponível em: <http://www.seagri.ba.gov.br/CafeConilon.htm>. Acesso em: 07 de julho de 2009.

50 SHANKARAYANA, M.L.; RAGHAVEN, B.; ABRAHAM, O.; NATARAJAN, C.P. Complex nature of coffee aroma. Indian Coffee, Bangalore, v.38, n.4, p. 84-92, Apr. 1974

51 SHIGEMATSU, H.; KURATA, T.; KATO, H.; FUJIMAKI, M. Volatile Compounds Formed on Roasting DL-a-Alanine with D-Glucose Agricultural Biology and Chemistry, v. 36, p. 1631-1637, 1972.

52 SIVETZ, M.; DESROSIER, N. W.; Coffee Technology, AVI Publishing Company, Inc., Connecticut, 1979, p. $256,563$.

53 STARBIRD, E. A. The Bonanza Bean - Coffee. National Geographic Magazine, 388-404, 1981.

54 STONE, H.; SIDEL, J. L. Sensory evaluation practices. 2nd ed. London: Academic Press. 1993.337 p. 
55 TRUGO, L. C. Encyclopedia of Food Sciences and Nutrition; Caballero, B.; Trugo, L. C.; Finglas, P. M., orgs.; Academic Press: London, v. 3, p. 1498, 2003.

56 VARNAM, A. H.; SUTHERLAND, J. P.; Bebidas: Tecnologia, Química y Microbiología. Acribia; Zaragoza, 1997; p. 259.

57 VIANI, R.; HORMAN, I. Thermal behaviour of trigonelline; Journal of Food Science,v.39, p. 1216 -1217, 1974.

58 WATTS, B.M., YLIMAKI, G.L., JEFFERY, L.E., ELIAS, L.G. Métodos sensoriais básicos para la evaluación de alimentos. Tradución: Oficina de Traducciones, Secretaria de Estado.Ottawa : Centro Internacional de Investigaciones para el Desarrollo, 1992. 170p.

59 YATE, D. K.; TUO, S. Contribution a l'amélioration de la qualité du café par le choix d'une torréfaction optimale. In: COLLOQUE SCIENTIFIQUE INTERNATIONAL SUR LE CAFÉ, 16. Kyoto (Japón), 1995. París (França), ASIC, p.886901, 1995 